\title{
Unraveling Oxygen Evolution in Li-Rich Oxides: A Unified Modeling of the Intermediate Peroxo/Superoxo-like Dimers
}

\author{
Zhenlian Chen ${ }^{\mathrm{a}, \mathrm{b}}$, Jun $\mathrm{Li}^{\mathrm{a} *}$ and Xiao Cheng Zeng ${ }^{\mathrm{b} *}$

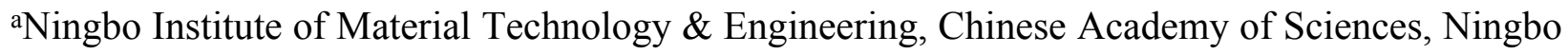 \\ 315201, China \\ ${ }^{b}$ Department of Chemistry, University of Nebraska-Lincoln, Lincoln, Nebraska 68588, United \\ States.
}

*Corresponding author: lijun@nimte.ac.cn ; xzeng1@unl.edu

Contents:

I. Coordination condition for dimer formation in Li-rich and Mn-rich layered cathode compounds $\left(\mathrm{Li}_{1+\mathrm{x}} \mathrm{Ni}_{\mathrm{y}} \mathrm{Co}_{\mathrm{z}} \mathrm{Mn}_{1-\mathrm{x}-\mathrm{y}-\mathrm{z}} \mathrm{O}_{2}\right)$.

II. Energy profiles for delithiation models.

III. $\mathrm{O}_{2}-\mathrm{O}_{2}$ intermolecular distance and magnetic moments.

IV. Partial charge density plots for peroxide $\mathrm{CaO}_{2}$, superoxide $\mathrm{LiO}_{2}$, triplet $\mathrm{O}_{2}$ and the Disorder model of $\mathrm{Li}_{1 / 2} \mathrm{MnO}_{3}$ as well as $\pi$ back-bonding in $\mathrm{Li}_{5 / 4} \mathrm{MnO}_{3}$. 
I. Coordination condition for dimer formation in Li-rich and Mn-rich layered cathode compounds $\left(\mathrm{Li}_{1+\mathrm{x}} \mathrm{Ni}_{\mathrm{y}} \mathrm{Co}_{\mathrm{z}} \mathrm{Mn}_{1-\mathrm{x}-\mathrm{y}-\mathrm{z}} \mathrm{O}_{2}\right)$.

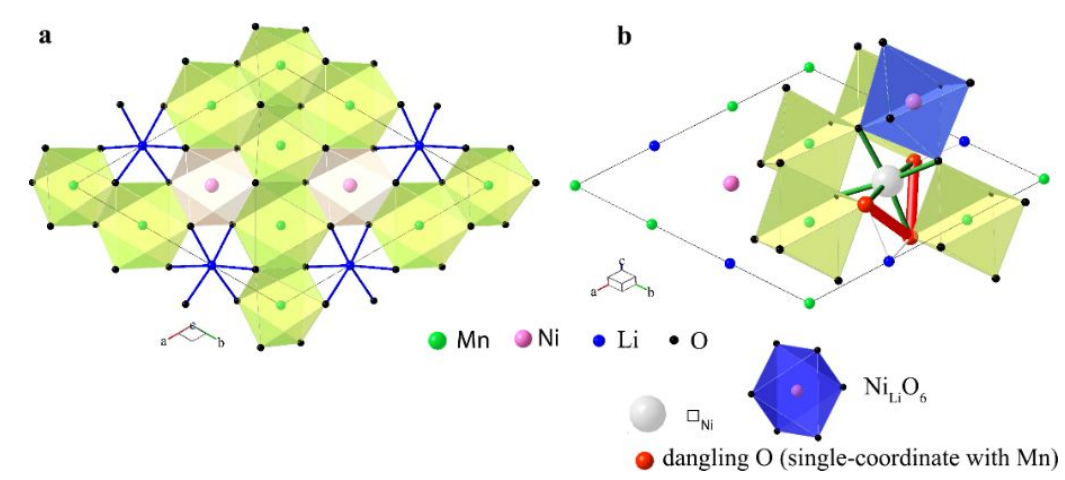

Figure S1 Illustration of coordination environment of oxygen ions, which can be changed by TM ion migration. a, A top view of the slab of TM layer for normal $\mathrm{Li}_{11 / 9} \mathrm{Mn}_{5 / 9} \mathrm{Ni}_{2 / 9} \mathrm{O}_{2}$, where the $\mathrm{MnO}_{6}, \mathrm{NiO}_{6}$ octahedra are presented in yellow-green and light pink, respectively. $\mathbf{b}$, A side view of $\mathrm{Ni}$ ion migration to first neighboring Li site (center at the blue octahedron). The red spheres represent the dangling oxygen ions which have only a single coordination with Mn ion.

a

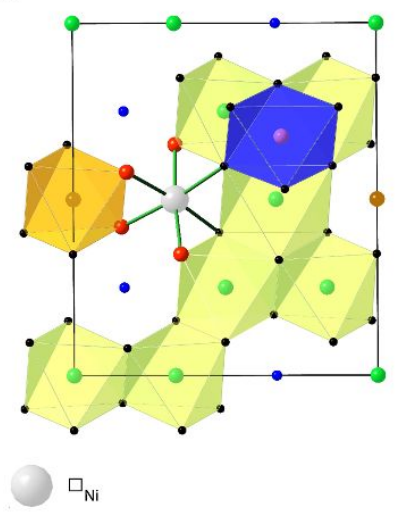

dangling O (single-coordinate with Mn) b

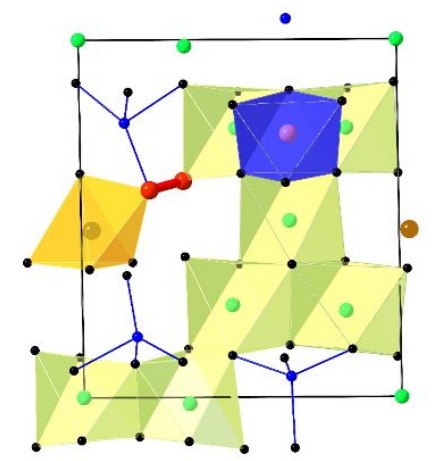

$\mathrm{Ni}_{\mathrm{Li}} \mathrm{O}_{6}$

O-O dimer $(1.3 \AA)$

Figure S2 The coordination environment of oxygen ions and dimer formation in a Migration model of monoclinic $\mathrm{Li}_{15} \mathrm{Mn}_{7} \mathrm{NiCoO}_{24}$ with $\mathrm{Ni}$ occupying a $\mathrm{Li}$ site in $\mathrm{Li}$ layer. a, A top view of the slab of TM layer for $\mathrm{Li}_{15} \mathrm{Mn}_{7} \mathrm{NiCoO}_{24}$, where the $\mathrm{MnO}_{6}, \mathrm{NiO}_{6}$ and $\mathrm{CoO}_{6}$ octahedra are presented in yellow-green, chocolate-brown and blue, respectively. b, A top view of $\mathrm{Li}_{3} \mathrm{Mn}_{7} \mathrm{NiCoO}_{24}$ with only $\mathrm{Li}$ ion in TM layer reserved in the delithiation model, where all the Li ions move to interstitial tetrahedral sites accompanied with Co moving to centering at a square-like pyramid. The O-O dimer is a bridge dimer connecting the $\mathrm{CoO}_{5}$ with a $\mathrm{MnO}_{6}$.

II. Energy profiles for delithiation models. 

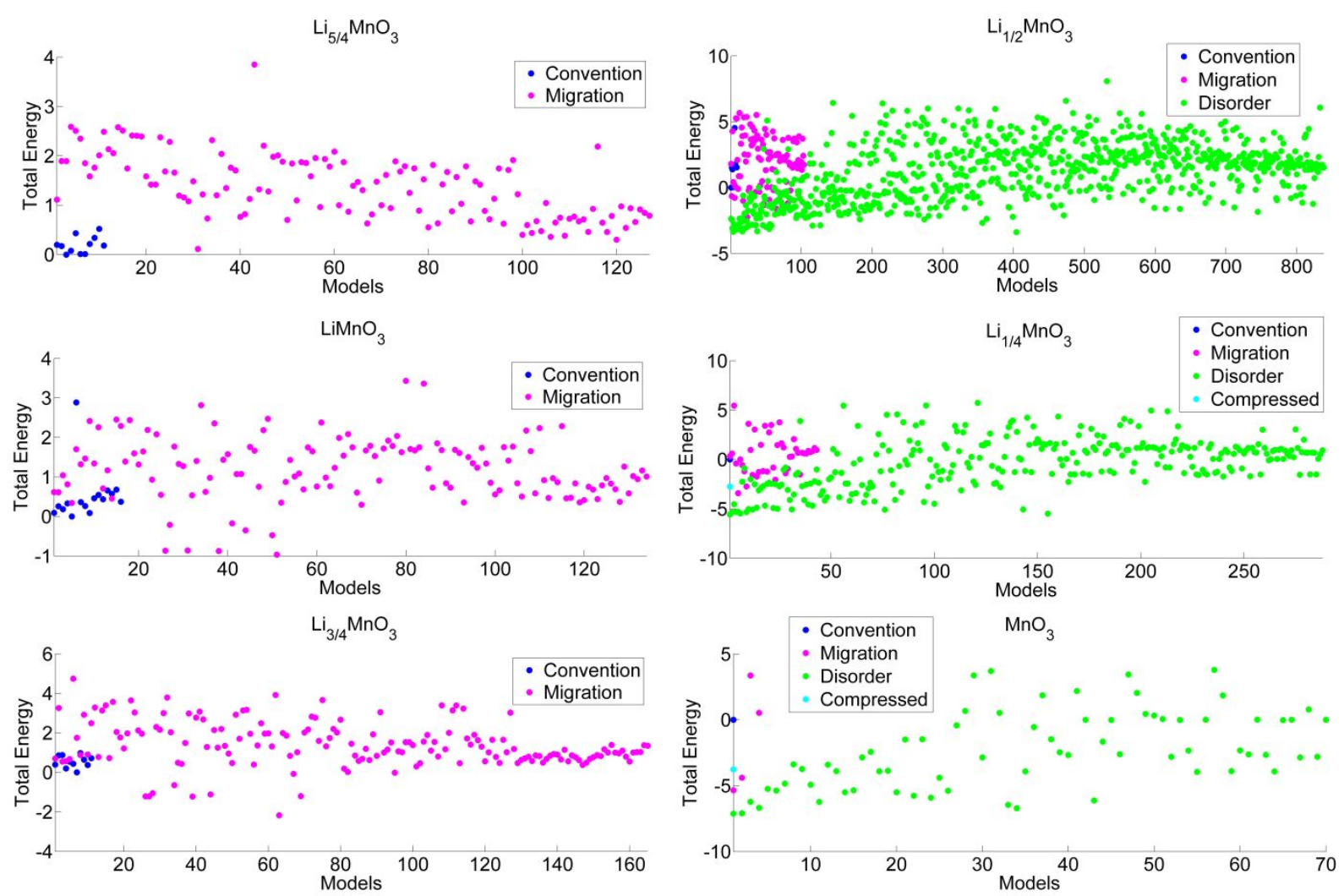

Figure S3 Energy profiles for the three kinds of delithiation models for $\mathrm{Li}_{2-\mathrm{x}} \mathrm{MnO}_{3}(\mathrm{x}=3 / 4 \sim 2)$.

III. Magnetic moments (MMs) of $\mathrm{O}_{2}-\mathrm{O}_{2}$ and intermolecular distance

Testing calculations are performed for full delithiation stage to investigate the quenching of MM. The MM value for each dimer is ca. $0.9 \mu_{\mathrm{B}}$ if only the two dimers are reserved in the unit cell (the lattice backbone is removed, cf. Figure S4), and it is ca. $1.6 \mu_{\mathrm{B}}$ for one dimer if the other $\mathrm{O}_{2}$ dimer is further removed from the unit cell. The value is ca. $1.4 \mu_{\mathrm{B}}$ if anti-ferromagnetic order is initialized for the $\mathrm{O}_{2}-\mathrm{O}_{2}$ array. The value is ca. $1.4 \mu_{\mathrm{B}}$ if one dimer is removed from the unit (the backbone lattice and one dimer is reserved). 


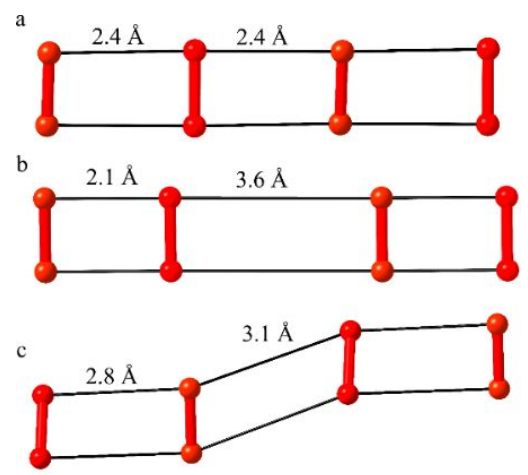

Figure $\mathrm{S} 4$ The $\mathrm{O}_{2}-\mathrm{O}_{2}$ distance in the three Disorder models. a Fully delithiated stage $\mathrm{MnO}_{3} \cdot \mathrm{b}$ $\mathrm{Li}_{1 / 4} \mathrm{MnO}_{3}$. c Li $i_{1 / 2} \mathrm{MnO}_{3}$.

IV. Partial charge density plots for peroxide $\mathrm{CaO}_{2}$, superoxide $\mathrm{LiO}_{2}$, triplet $\mathrm{O}_{2}$ and the Disorder model of $\mathrm{Li}_{1 / 2} \mathrm{MnO}_{3}$ as well as $\pi$ back-bonding in $\mathrm{Li}_{5 / 4} \mathrm{MnO}_{3}$.
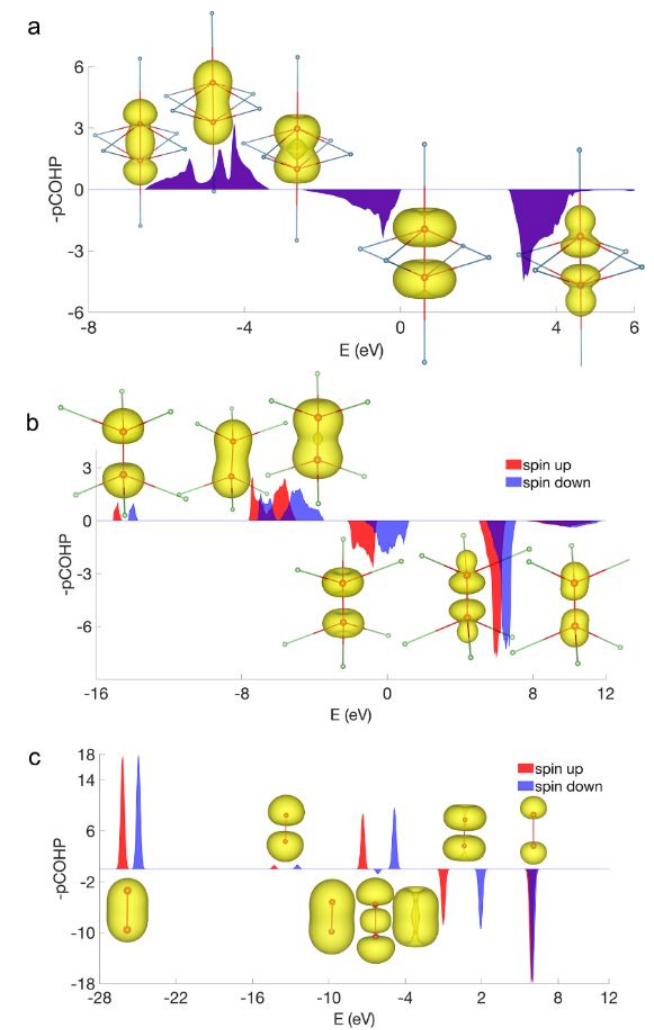

Figure S5 The energy decomposed partial charge density. a, Peroxo in $\mathrm{CaO}_{2}$. Where $\mathrm{Ca}$ is represented with small blue sphere. $\mathbf{b}$, Superoxo in $\mathrm{LiO}_{2}$. Where $\mathrm{Li}$ is represented with small green sphere. $\mathbf{c}$, triplet oxygen molecule. The positive value of $-\rho \mathrm{COHP}$ means bonding and negative antibonding. The dimer moiety is presented with two red spheres lined with a red stick. 

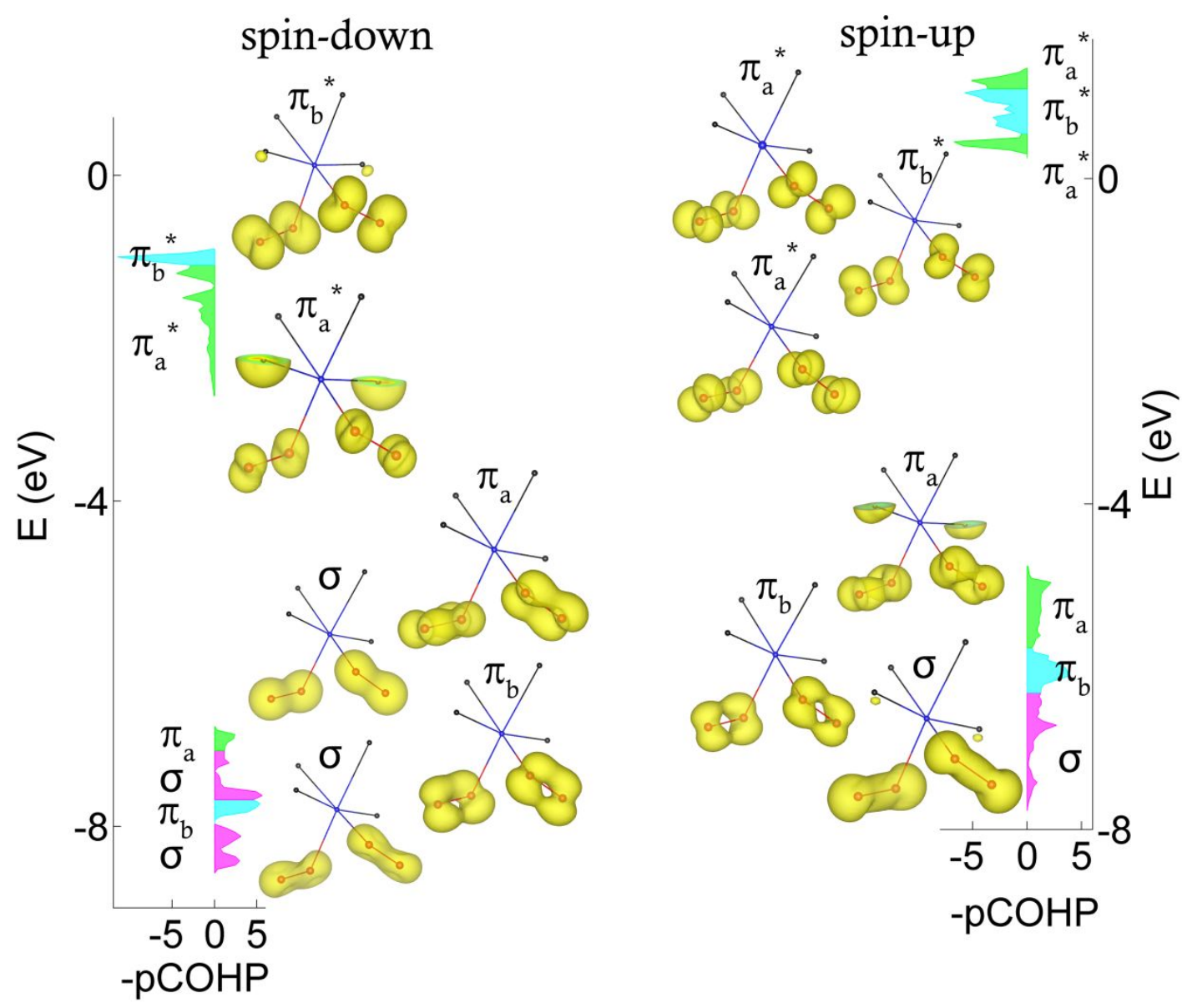

Figure S6 The energy-decomposed partial charge density plots (top view along $b$ axis) of Disorder model for $\mathrm{Li}_{1 / 2} \mathrm{MnO}_{3}$. The green, magenta and cyan region in COHP analysis correspond to $\pi_{\mathrm{a}}$ $\left(\pi_{\mathrm{a}}{ }^{*}\right), \pi_{\mathrm{b}}\left(\pi_{\mathrm{b}}{ }^{*}\right)$ and $\sigma_{\mathrm{c}}\left(\sigma_{\mathrm{c}}{ }^{*}\right)$, respectively. The positive value of $-\rho$ COHP means bonding, while negative value means antibonding. The green, blue and black spheres represent $\mathrm{Mn}, \mathrm{Li}$ and lattice oxygen ions, respectively. And dimer moiety is presented with two red spheres lined with a red stick. 


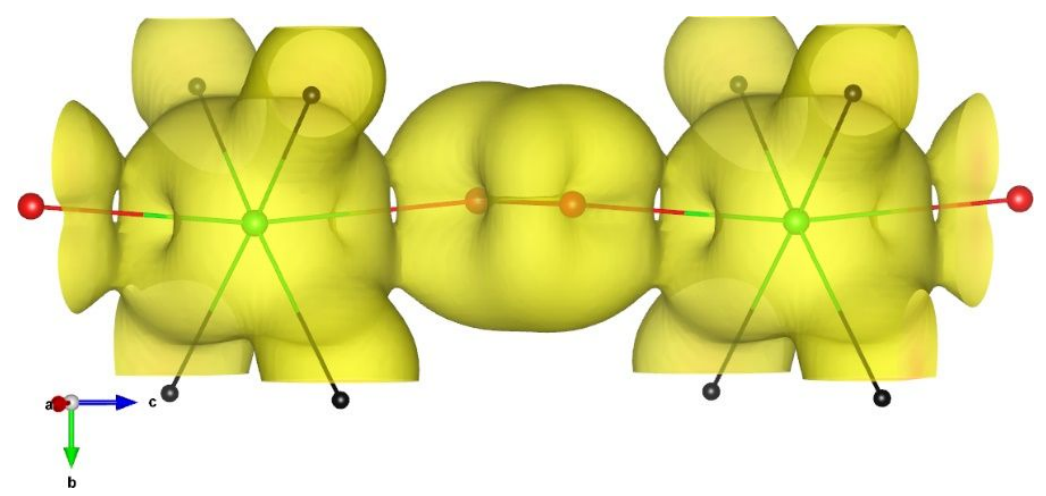

Figure S7 The energy-decomposed partial charge density plots for $\mathrm{Li}_{5 / 4} \mathrm{MnO}_{3}$ in the energy range of spin-up O-O $\pi_{\mathrm{b}}$ bonding. The green and black spheres present $\mathrm{Mn}$ and lattice oxygen ions, respectively. And dimer moiety is presented with two red spheres lined with a red stick. 